\title{
Late recovery of atrioventricular conduction after postsurgical chronic atrioventricular block is not exceptional
}

\author{
Irene E. van Geldorp, $\mathrm{MD},{ }^{\mathrm{a}, \mathrm{c}}$ Ward Y. Vanagt, $\mathrm{MD}, \mathrm{PhD},{ }^{\mathrm{b}, \mathrm{c}, \mathrm{d}}$ Guusje Vugts, $\mathrm{BSc},{ }^{\mathrm{a}}$ Rik Willems, MD, PhD, \\ Filip Rega, MD, PhD, ${ }^{f}$ Marc Gewillig, MD, PhD, ${ }^{\mathrm{d}}$ and Tammo Delhaas, $\mathrm{MD}, \mathrm{PhD}^{\mathrm{a}, \mathrm{c}}$
}

\begin{abstract}
Objective: Postsurgical atrioventricular block may complicate surgery for congenital heart defects and is generally considered permanent when persisting longer than 14 days after surgery. In this study, we evaluate the occurrence of spontaneous late recovery of atrioventricular conduction in postsurgical chronic atrioventricular block and discuss its clinical implications.
\end{abstract}

\begin{abstract}
Methods: We retrospectively reviewed all cardiac surgical procedures on cardiopulmonary bypass between January 1993 and November 2010 in subjects younger than 18 years. Patients with postsurgical advanced second- or third-degree atrioventricular block persisting longer than 14 days after surgery were included.
\end{abstract}

Results: Of a total of 2850 cardiac surgical procedures on cardiopulmonary bypass, 59 (2.1\%) were immediately complicated by chronic postsurgical atrioventricular block of advanced second $(n=4)$ or third degree $(\mathrm{n}=55)$. In another 6 patients $(0.2 \%)$, late occurrence of chronic advanced second- $(\mathrm{n}=3)$ or third-degree $(\mathrm{n}=3)$ atrioventricular block, without signs of any etiology other than previous surgery, was seen 0.4 to 10 years after surgery (median, 5.7 years). Late ( $>2$ weeks) regression to either completely normal atrioventricular conduction or asymptomatic first-degree atrioventricular block occurred 3 weeks to 7 years (median, 3.1 years) after surgery in $7(12 \%)$ patients with immediate postsurgical chronic atrioventricular block.

Conclusions: Complete recovery of atrioventricular conduction or regression to asymptomatic first-degree atrioventricular block occurred in $12 \%$ of patients with postsurgical chronic second- or third-degree atrioventricular block. To prevent unnecessary adverse side effects of chronic ventricular pacing and to prolong battery longevity, ventricular pacing should be minimized in patients with recovered normal atrioventricular conduction. (J Thorac Cardiovasc Surg 2013;145:1028-32)

Postsurgical complete atrioventricular (AV) block complicates approximately $3 \%$ of all surgical procedures for congenital heart defects involving cardiopulmonary bypass. ${ }^{1}$ Postsurgical AV block persisting after 7 to 14 days is usually considered to be permanent and is a class I indication for implantation of a permanent pacemaker. ${ }^{2}$ Although some retrospective studies have reported late recovery of $\mathrm{AV}$ conduction in patients who were considered to have permanent postsurgical AV block, ${ }^{3,4}$ such recovery is generally thought to be exceptional. It is of clinical importance to identify patients in whom permanent pacing could

From the Departments of Biomedical Engineering ${ }^{\mathrm{a}}$ and Physiology, ${ }^{\mathrm{b}}$ Cardiovascular Research Institute Maastricht, Maastricht University, Maastricht, The Netherlands; the Department of Pediatrics, ${ }^{\mathrm{c}}$ Maastricht University Medical Center, Maastricht, The Netherlands; and the Departments of Pediatric Cardiology, ${ }^{\mathrm{d}}$ Cardiology, and Cardiac Surgery, ${ }^{\mathrm{f}}$ University Hospitals Leuven, Leuven, Belgium.

Supported by grants of the Dutch Heart Foundation NHS-2010T078 (to I.E.v.G.) and NHS-2010T042 (to W.Y.V.).

Disclosures: Authors have nothing to disclose with regard to commercial support.

Received for publication Feb 8, 2012; revisions received March 27, 2012; accepted for publication May 7, 2012; available ahead of print June 13, 2012.

Address for reprints: Irene E. van Geldorp, MD, Department of Biomedical Engineering, Cardiovascular Research Institute Maastricht, Maastricht University, PO Box 616, NL-6200 MD, Maastricht, The Netherlands (E-mail: i.vangeldorp@ maastrichtuniversity.nl).

$0022-5223 / \$ 36.00$

Copyright (c) 2013 by The American Association for Thoracic Surgery doi:10.1016/j.jtcvs.2012.05.012 be avoided, however, because permanent conventional ventricular pacing for complete $\mathrm{AV}$ block is associated with decreased left ventricular function and an increased risk of heart failure. ${ }^{5}$ The main objective of this study was therefore to determine the incidence of recovery of AV conduction after postsurgical chronic AV block and to discuss its clinical implications.

\section{MATERIALS AND METHODS Study Population}

All patients with AV block after surgery for congenital heart disease undergone at an age younger than 18 years between January 1, 1993, and November 1, 2010, were retrospectively selected from the database of the department of Pediatric Cardiology of University Hospitals Leuven (Leuven, Belgium). Charts of all patients with either AV block or a pacemaker implanted after surgery were reviewed. Patients with advanced second-degree or complete AV block persisting longer than 14 days after cardiac surgery were included, whereas patients with congenital or preexisting AV block were excluded. From the included patients, the following data were obtained: date of birth, cardiac diagnosis, type and date of surgery after which AV block occurred, and degree of AV block. Follow-up data on patients status were obtained from the (at least) biannual routine visit to University Hospitals Leuven or the referring centers.

\section{Outcome Measures}

Advanced second-degree and complete postsurgical AV blocks that persisted longer than 14 postoperative days were considered to represent postsurgical chronic AV block. Late occurrence of postsurgical AV block was 


\section{Abbreviation and Acronym}

$\mathrm{AV}=$ atrioventricular

characterized by the occurrence of second-degree or complete chronic AV block after the immediate (14 days) postsurgical period in the absence of familial or infectious etiology. Regression from postsurgical chronic AV block either to completely normal AV conduction (PQ time $<0.2$ seconds) or to asymptomatic first-degree AV block was considered to represent late recovery of AV conduction.

\section{RESULTS}

\section{Incidence of Postsurgical Chronic Advanced}

Second- or Third-Degree AV Block

Between January 1, 1993, and November 1, 2010, a total of 2850 cardiac surgical procedures with cardiopulmonary bypass were performed in children. From the database, 59 cases $(2.1 \%)$ were identified in which surgery was immediately complicated by postsurgical chronic AV block of advanced second $(n=4)$ or third degree $(n=55)$. Three of these patients died within the postoperative period before discharge but later than 14 days after surgery. These patients were considered to have postsurgical chronic AV block without recovery.

Late occurrence of chronic advanced second-degree $(\mathrm{n}=3)$ or third-degree $(\mathrm{n}=3)$ AV block, without signs pointing to any etiology other than previous surgery, was found in 6 additional patients $(0.2 \%)$ at 0.4 to 10 years after surgery (median, 5.7 years). Only 1 of these patients with late occurrence of chronic AV block also had transient complete AV block in the immediate postsurgical period after closure of a ventricular septal defect.

Summing up, the overall incidence of immediate and late postsurgical chronic AV block of advanced degree was 65 of $2850(2.3 \%)$. The results are schematically represented in Figure 1.

Among the patients with immediate and late postsurgical chronic $\mathrm{AV}$ block, surgery was performed at an age of 0 to 16 years (median, 0.9 years). The various types of surgical interventions resulting in AV block are presented in Table 1. For each surgical procedure, a risk-percentage is indicated; however, some of these risk-percentages are based on relatively small numbers of patients and have undoubtedly been influenced by chance.

\section{Late Recovery of AV Conduction After Postsurgical Chronic AV Block}

Late improvement in AV conduction was observed in $12 \%$ of the patients with immediate postsurgical chronic AV block (Figure 1 and Table 2). Four patients (6.8\%) showed completely normal AV conduction at 23 days, 11 weeks, 6.8 years, and 7.0 years after immediate postsurgical complete chronic AV block. Regression of postsurgical chronic AV block of advanced degree to asymptomatic first-degree AV block was observed in 3 additional patients $(5.1 \%)$ at 22 days, 3.1 years, and 6.2 years after surgery. In 2 of the latter patients, even completely normal AV conduction was observed during further follow-up (after 22 days +4.6 years and $6.2+1.1$ years, respectively). Regression toward normal $\mathrm{AV}$ conduction was not observed in the 6 patients with late occurrence of AV block.

\section{Follow-up of Patients With Recovered AV Conduction}

Follow-up after recovery of AV conduction varied between 2 months and 7 years (median follow-up was 3.5 years). During follow-up, 1 patient died of Klebsiella sepsis 2 months after recovery of completely normal AV conduction, and 1 patient had a relapse into complete AV block 3.5 years after recovery of completely normal AV conduction. When recovery of AV conduction was recognized, pacemakers were left in situ, and battery longevity was prolonged by adjustment of the pacemaker settings to a backup mode.

\section{DISCUSSION}

Postsurgical AV block is usually considered to be permanent if it persists after 7 to 14 days. $^{2}$ In $12 \%$ of our study population of 59 patients with immediate postsurgical chronic second- or third-degree AV block, however, either complete recovery of $\mathrm{AV}$ conduction or regression to asymptomatic first-degree AV block occurred between 3 weeks and 7 years after surgery.

\section{Recovery of AV Conduction After Postsurgical AV Block}

It is well known that postsurgical AV block may resolve spontaneously within the first days after surgery. About $50 \%$ of postsurgical complete AV blocks will resolve within the first week, and about $63 \%$ within 30 days after surgery. ${ }^{1}$ The possibility of postsurgical AV block resolving years after surgery, however, is less well recognized.

The first description of very late recovery of AV conduction after complete postsurgical AV block was given in 1976 by Reid and associates, ${ }^{4}$ who described a patient with spontaneous reversion to (persisting) normal AV conduction after an interval of 11 years. In the subsequent era of 1976 through 1996, Bruckheimer and colleagues ${ }^{6}$ found recovered AV conduction in $32 \%$ of 44 patients receiving pacemakers for postsurgical AV block, with a median follow-up until recognition of recovery of 5.5 years (range, 0.1-20 years). The incidence of recovered AV conduction was $21 \%$ when only patients with pacemaker implantation later than 14 days after surgery were considered. More recently, Batra and coworkers ${ }^{3}$ reported recovery of AV conduction within the first 6 months after surgery in $9.6 \%$ of 72 patients with a complete AV block persisting beyond 14 days after surgery. ${ }^{3}$ The differences between these studies 


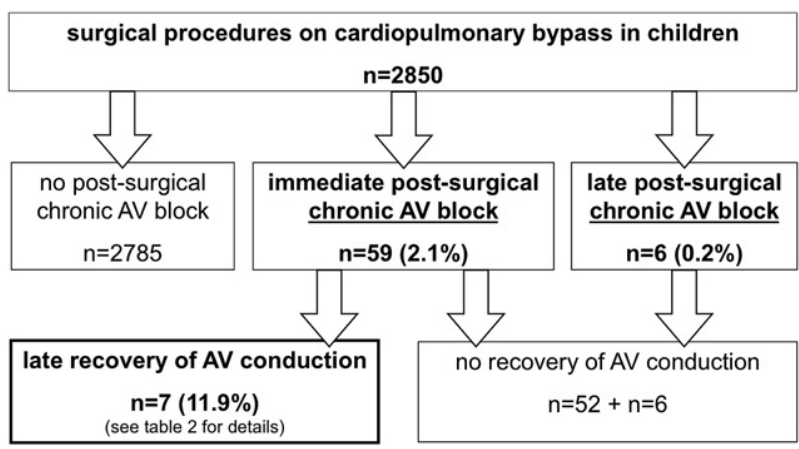

FIGURE 1. Schematic overview of results. Chronic atrioventricular $(A V)$ block was considered to be atrioventricular block of advanced second or third degree persisting longer than 14 days.

and our own may be explained by the small number of patients in each study, which increases the influence of chance. Moreover, the eras of investigation, the diverse retrospective search strategies and structures of databases, and the slightly varying inclusion criteria are also factors. It might be disputed whether the patient in our series with recovered conduction and relapse into advanced AV block 3.5 years later truly ought to be included with the other 6 patients with recovered $\mathrm{AV}$ conduction. If that patient were not counted as a patient with recovered AV conduction, the $11.9 \%$ recovery rate would drop to $10.2 \%$.

\section{Onset of Postsurgical AV Block After the Immediate Postsurgical Period}

We identified 6 patients of $2850(0.2 \%)$ with late onset of chronic postsurgical AV block, which occurred as late as 10

TABLE 1. Postsurgical chronic atrioventricular block by type of surgery

\begin{tabular}{lccr}
\hline \multicolumn{1}{c}{ Type of surgery } & $\begin{array}{c}\text { Total } \\
(\mathbf{n})\end{array}$ & $\begin{array}{c}\text { Chronic AV } \\
\text { block (n) }\end{array}$ & $\begin{array}{c}\text { Risk } \\
(\%)\end{array}$ \\
\hline VSD procedures & 1194 & 31 & 2.6 \\
$\quad$ VSD closure & & 11 & 1.7 \\
$\quad$ VSD closure in complex congenital & & $18^{*}$ & 3.2 \\
$\quad$ heart disease & & & \\
$\quad$ VSD enlargement & 244 & 14 & 5.7 \\
AV septal defect correction & 33 & 4 & 12.1 \\
Tricuspid valve procedures & 61 & $3 \dagger$ & 4.9 \\
Mitral valve procedures & 111 & $10 \ddagger$ & 9.0 \\
Left ventricular outflow tract procedures & 377 & 1 & 0.3 \\
Atrial septal defect closure (surgical) & 830 & 2 & 0.2 \\
Other & &
\end{tabular}

$A V$, Atrioventricular block; $V S D$, ventricular septal defect. *Complex congenital heart disease included tetralogy of Fallot ( $\mathrm{n}=2$ with postsurgical chronic AV block), transposition of the great arteries ( $\mathrm{n}=9$ with postsurgical chronic $\mathrm{AV}$ block), double-outlet right ventricle ( $\mathrm{n}=3$ with postsurgical chronic AV block), VSD and left ventricular outflow tract obstruction ( $\mathrm{n}=3$ with postsurgical chronic AV block), and truncus arteriosus ( $\mathrm{n}=1$ with postsurgical chronic AV block). $\dagger$ Two patients had surgery for the left ventricular outflow tract within the same surgical procedure. $\ddagger$ One patient had tricuspid valve surgery within the same surgical procedure. years after surgery (median, 5.7 years; range, 0.4-10 years). The true incidence of late onset of AV block following surgery, however, is difficult to determine because its discovery at least requires careful follow-up for a lifetime. Furthermore, when conduction disturbances are recognized many years after surgery, it may be unclear whether they are directly related to the surgical intervention. It has been suggested that late onset of AV block is associated with transient AV block in the immediate postsurgical period and with persisting conduction disorders such as left or right bundle branch block ${ }^{7,8}$; however, late onset of AV block has also been observed in patients without any history of conduction disorders. ${ }^{9}$ In our study, only one of the six patients with late onset of AV block had transient third-degree $\mathrm{AV}$ block in the immediate postoperative period.

\section{Avoiding Unnecessary Ventricular Pacing in Patients With Postsurgical Chronic AV Block}

Pacemaker implantation improves the outcome of (postsurgical) advanced second- or third-degree AV block. When pacing became available, a significant reduction in mortality from postsurgical AV block was reported. ${ }^{10}$ In addition to the obvious beneficial effects of the restoration of heart rate, the unpredictable risk of sudden cardiac death and left ventricular failure associated with untreated complete heart block are treated by chronic ventricular pacing. ${ }^{11,12}$ Weindling and colleagues ${ }^{1}$ concluded that there is minimal benefit in delaying pacemaker implantation beyond 9 days after surgery, because $97 \%$ of the patients who show recovery of AV conduction do so within the first 9 postoperative days. Postsurgical AV block persisting longer than 7 to 14 days is therefore usually considered to be permanent and is a class I indication for implantation of a permanent pacemaker. ${ }^{2}$ Without exception, however, ventricular pacing induces an abnormal electrical activation pattern, which may cause adverse mechanical dyssynchrony. Conventional ventricular pacing is associated with impairment of pump function, left ventricular remodeling, and increased risk of heart failure. ${ }^{13-16}$ Because normal intrinsic activation patterns are superior to the activation patterns induced by conventional pacing, ventricular pacing should be avoided (or minimized) in patients with (partially) preserved $\mathrm{AV}$ conduction and an intact His-Purkinje system. ${ }^{5,17}$

\section{Clinical Implications}

Chronic AV block of advanced degree is an important complication of surgery for congenital heart disease. To inform patients and parents adequately about this complication and its prognosis, surgeons and cardiologists should be aware of the possibility of postsurgical AV block regression, even many years after surgery. Moreover, to prevent unnecessary adverse side effetcs of chronic ventricular pacing, we think that it is of clinical importance to identify patients in whom permanent pacing may be avoidable. Raised 
TABLE 2. Characteristics of patients with recovery of atrioventricular conduction after postsurgical chronic atrioventricular block

\begin{tabular}{|c|c|c|c|c|c|}
\hline Case & Heart disease & $\begin{array}{c}\text { Procedure and timing } \\
\text { (age }[y] \text { and year of surgery) }\end{array}$ & $\begin{array}{l}\text { Chronic postsurgical } \\
\text { AV block }\end{array}$ & $\begin{array}{l}\text { Time to recovery } \\
\text { of conduction }\end{array}$ & Follow-up* \\
\hline 1 & AVSD & AVSD correction $(4.0 \mathrm{y} ; 2006)$ & Complete & $22 \mathrm{~d} ; 4.7 \mathrm{y}$ & $\begin{array}{l}\text { Asymptomatic first-degree AV block } \\
\text { completely normal AV conduction } \\
4.6 \text { y later }(5.1 \mathrm{y})\end{array}$ \\
\hline 2 & D-TGA, VSD, PS & VSD closure $(2.6 \mathrm{y} ; 2007)$ & Complete & $23 \mathrm{~d}$ & $\begin{array}{l}\text { Normal AV conduction until death } \\
\quad(\text { Klebsiella sepsis })(2 \mathrm{mo})\end{array}$ \\
\hline 3 & Isolated VSD & VSD closure (5.9 y; 2003) & Complete & $11 \mathrm{wk}$ & $\begin{array}{l}\text { Normal AV conduction during } 3.5 \mathrm{y} \text {; } \\
\text { subsequent relapse into complete } \\
\text { AV block }(7 \mathrm{y})\end{array}$ \\
\hline 4 & AVSD & AVSD correction (6.2 y; 1996) & Second degree (advanced) & $3.1 \mathrm{y}$ & $\begin{array}{l}\text { Asymptomatic first-degree AV block } \\
(3.5 \mathrm{y})\end{array}$ \\
\hline 5 & AVSD & AVSD correction $(0.6 \mathrm{y} ; 2003)$ & Second degree (advanced) & $6.2 \mathrm{y} ; 7.3 \mathrm{y}$ & $\begin{array}{l}\text { Asymptomatic first-degree AV block } \\
\text { completely normal AV conduction } \\
1.1 \text { y later }(7.8 \mathrm{y})\end{array}$ \\
\hline 6 & AS (bicuspid) & LVOT (Ross) procedure ( $4.5 \mathrm{y} ; 2004)$ & Complete & $6.8 \mathrm{y}$ & Normal AV conduction (11 mo) \\
\hline 7 & AVSD & AVSD correction (0.3 y; 2000) & Complete & $7.0 \mathrm{y}$ & Normal AV conduction (3.9 y) \\
\hline
\end{tabular}

$A S$, Aortic valve stenosis; $A S D$, atrial septal defect; $A V$, atrioventricular; $A V S D$, atrioventricular septal defect; $D$ - $T G A$, dextrotransposition of the great arteries; $L V O T$, left ventricular outflow tract; $P S$, pulmonary stenosis; $V S D$, ventricular septal defect. *Duration of follow-up after recovery is given in parentheses.

awareness of the existence of recovery of AV conduction after chronic postsurgical AV block will therefore also be important for physicians who follow up patients with postsurgical AV block and a pacemaker. In the patient with recovered AV conduction, the ventricular pacemaker should be reprogrammed as a back-up device to avoid adverse effects of unnecessary ventricular pacing and to prolong battery longevity. Because of the potential risk of recurrence of AV block in patients with a history of postsurgical AV block (1 of our patients with recovered normal AV conduction had a relapse into complete AV block 3.5 years later) and because of the clinical importance of a recurrent AV block, it may be best practice to keep the device in situ and to replace the generator if the battery is depleted. It is recommended that cardiologists providing long-term follow-up care of patients with surgery for congenital heart disease should be alert to the issue of late incidence of postsurgical AV block and respond promptly and proactively to suggestive symptoms such as syncope. Cardiologists should undertake heart rhythm monitoring at regular intervals in symptom-free patients, because an AV block that may unexpectedly present many years after surgery is potentially life threatening. ${ }^{8,9,18,19}$

\section{Study Limitations}

The retrospective nature of the study is a limitation. In addition, intermittent follow-up means that the exact date of recovery of $\mathrm{AV}$ conduction could not precisely be assessed. As in other studies on this subject, the population of our study was too small and too heterogeneous to identify positive prognostic factors for recovery of AV block, such as the underlying defect, surgical techniques, or immediate postoperative period. To permit analysis of predictors for either the occurrence of immediate or late postsurgical AV block or the occurrence of recovery of AV conduction after postsurgical chronic AV block, further research should be performed in larger (multicenter) study populations. Because of the low incidence of chronic postsurgical AV block, prospective studies with large patient numbers are hard to perform.

\section{CONCLUSIONS}

In our study population of 59 patients with immediate chronic postsurgical second- or third-degree AV block, either complete recovery of $\mathrm{AV}$ conduction or regression to asymptomatic first-degree AV block occurred between 3 weeks and 7 years after surgery in $12 \%$ of the patients. To prevent unnecessary adverse side effects of chronic ventricular pacing and to prolong battery longevity, it is important to minimize ventricular pacing by reprogramming the pacemaker as a backup device in patients with recovered normal AV conduction.

\section{References}

1. Weindling SN, Saul JP, Gamble WJ, Mayer JE, Wessel D, Walsh EP. Duration of complete atrioventricular block after congenital heart disease surgery. Am J Cardiol. 1998;82:525-7.

2. Epstein AE, DiMarco JP, Ellenbogen KA, Estes NA 3rd, Freedman RA, Gettes LS, et al. ACC/AHA/HRS 2008 Guidelines for Device-Based Therapy of Cardiac Rhythm Abnormalities: a report of the American College of Cardiology/American Heart Association Task Force on Practice Guidelines (Writing Committee to Revise the ACC/AHA/NASPE 2002 Guideline Update for Implantation of Cardiac Pacemakers and Antiarrhythmia Devices) developed in collaboration with the American Association for Thoracic Surgery and Society of Thoracic Surgeons. J Am Coll Cardiol. 2008;51:e1-62. Erratum in: J Am Coll Cardiol. 2009;53:1473. Erratum in: J Am Coll Cardiol. 2009;53:147.

3. Batra AS, Wells WJ, Hinoki KW, Stanton RA, Silka MJ. Late recovery of atrioventricular conduction after pacemaker implantation for complete heart block associated with surgery for congenital heart disease. J Thorac Cardiovasc Surg. 2003;125:1291-3.

4. Reid JM, Coleman EN, Doig W. Reversion to sinus rhythm 11 years after surgically induced heart block. Br Heart J. 1976;38:1217-9. 
5. van Geldorp IE, Vanagt WY, Prinzen FW, Delhaas T. Chronic ventricular pacing in children: toward prevention of pacing-induced heart disease. Heart Fail Rev. 2011;16:305-14.

6. Bruckheimer E, Berul CI, Kopf GS, Hill SL, Warner KA, Kleinman CS, et al. Late recovery of surgically-induced atrioventricular block in patients with congenital heart disease. J Interv Card Electrophysiol. 2002;6:191-5.

7. Krongrad E. Prognosis for patients with congenital heart disease and postoperative intraventricular conduction defects. Circulation. 1978;57:867-70.

8. Lin A, Mahle WT, Frias PA, Fischbach PS, Kogon BE, Kanter KR, et al. Early and delayed atrioventricular conduction block after routine surgery for congenital heart disease. J Thorac Cardiovasc Surg. 2010;140:158-60.

9. Liberman L, Pass RH, Hordof AJ, Spotnitz HM. Late onset of heart block after open heart surgery for congenital heart disease. Pediatr Cardiol. 2008;29:56-9.

10. Lillehei CW, Sellers RD, Bonnabeau RC, Eliot RS. Chronic postsurgical complete heart block. With particular reference to prognosis, management, and a new P-wave pacemaker. J Thorac Cardiovasc Surg. 1963;46:436-56.

11. Udink ten Cate FE, Breur JM, van Woerkom JM, Kruize AA, Stoutenbeek P, Meijboom EJ. [Congenital complete atrioventricular block in children: pathogenesis and clinical outcomes]. Ned Tijdschr Geneeskd. 2002;146:1777-81. Dutch.

12. Michaelsson M, Riesenfeld T, Jonzon A. Natural history of congenital complete atrioventricular block. Pacing Clin Electrophysiol. 1997;20(8 Pt 2):2098-101.
13. Tantengco MV, Thomas RL, Karpawich PP. Left ventricular dysfunction after long-term right ventricular apical pacing in the young. J Am Coll Cardiol. 2001;37:2093-100.

14. Karpawich PP. Chronic right ventricular pacing and cardiac performance: the pediatric perspective. Pacing Clin Electrophysiol. 2004;27(6 Pt 2):844-9.

15. Thambo JB, Bordachar P, Garrigue S, Lafitte S, Sanders P, Reuter S, et al. Detrimental ventricular remodeling in patients with congenital complete heart block and chronic right ventricular apical pacing. Circulation. 2004;110:3766-72.

16. van Geldorp IE, Delhaas T, Gebauer RA, Frias P, Tomaske M, Friedberg MK, et al. Impact of the permanent ventricular pacing site on left ventricular function in children: a retrospective multicentre survey. Heart. 2011;97:2051-5.

17. Janousek J, Tomek V, Chaloupecky V, Gebauer RA. Dilated cardiomyopathy associated with dual-chamber pacing in infants: improvement through either left ventricular cardiac resynchronization or programming the pacemaker off allowing intrinsic normal conduction. J Cardiovasc Electrophysiol. 2004;15:470-4.

18. Goldman BS, Williams WG, Hill T, Hesslein PS, McLaughlin PR, Trusler GA, et al. Permanent cardiac pacing after open heart surgery: congenital heart disease. Pacing Clin Electrophysiol. 1985;8:732-9.

19. Gross GJ, Chiu CC, Hamilton RM, Kirsh JA, Stephenson EA. Natural history of postoperative heart block in congenital heart disease: implications for pacing intervention. Heart Rhythm. 2006;3:601-4. 